$16^{\text {th }}$ International Conference on

AEROSPACE SCIENCES \& AVIATION TECHNOLOGY,

ASAT - 16 - May 26 - 28, 2015, E-Mail: asat@ mtc.edu.eg

Military Technical College, Kobry Elkobbah, Cairo, Egypt

Tel : +(202) 24025292 - 24036138, Fax: +(202) 22621908

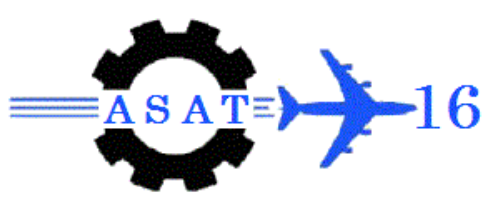

\title{
ALUMINIZED POLYETHYLENE REGRESSION RATE EVALUATION FOR HYBRID ROCKET MOTOR
}

\author{
Ah. El-S. Makled*
}

\begin{abstract}
Hybrid rocket solid fuel grain regression rate is one of the significant values to accurately determine in the hybrid rocket motor (HRM) design parameters and performance prediction. The comprehensive method to measure and evaluate HRM solid fuel regression rate was investigated theoretically and experimentally. The mathematical model has been introduced and a computer program was built to describe HRM regression rate. A series of experimental tests using a small scale HRM employs Polyethylene (PE) and aluminized PE as solid fuel (up to 15\% by mass metal powder additive) with different initial port diameter of fuel grain $(5,20$ and $28 \mathrm{~mm}$ ) and gaseous oxygen (GO2) as oxidizer to evaluate the HRM regression rate performance. The measured experimental data are compared with results obtained from theoretical computation. The comparison shows good agreement, which proves the validity of the developed program. Regression rate of hybrid fuel grain was enhanced by addition of $\mathrm{Al}$ powder compared to basic configuration $(0 \% \mathrm{Al})$ and it was found that it is more significant to use $\mathrm{Al}$ powder additive increased up to $7.5 \%$ by mass
\end{abstract}

\section{KEY WORDS}

Hybrid Rocket Motor, Regression rate, metal powder additive, Polyethylene.

\section{1: INTRODUCTION}

Hybrid propulsion systems (HPS) have inherent higher density impulse, safety, cost, pollution impact, on-off operations, control capability and operational features that make them an attractive choice for a broad range of applications, including boosting phase propulsion for launch vehicles [1,2], upper stage propulsion [1,2,3], tactical and strategic missile system $[1,4]$, in addition to the field of commercial space transportation [5].

HPS is the type of chemical propulsion systems that employs propellant ingredients physically separated by phase; this is the major source of safety.

A simplified schematic-diagram of classical hybrid rocket propulsion is given in Figure (1).

The classical HPS comprises an inert solid fuel grain with the injection of oxidizer (gas or liquid) in combustion channel port area of solid fuel grain (SFG).

The regression rate and combustion processes in the HRM are characterized by complex interactions between numerous physical phenomena taking place simultaneously in the combustion channel of SFG (oxidizer atomization, solid-fuel pyrolysis, heat transfer (convective and radiative), vaporization, gas-phase diffusion, mixing ,turbulent flow, reaction and combustion with varying fuel grain port configuration).

* Ph.D., Egyptian Armed forces 
The hybrid propellant was burnt in a turbulent diffusion flame zone over the burning surface; it is a very important design and performance parameter, which is strongly affected by the operating conditions, propellant combination and ingredients.

The effects of adding energetic materials on the SFG to enhance the regression rate are of much interest to the development of performance prediction like solid propellant.

Due to the mechanism of the hybrid propellant combustion, low regression rate $(\approx 1 / 3$ time of that of solid propellants) results from the poor heat transfer process between flame zone and solid fuel grain burning surface.

The regression behavior of a hybrid engine fuel grain differs considerably from that of a solid rocket propellant. Table (1) presents a comparison of the regression behaviors of solid motor and HRM.

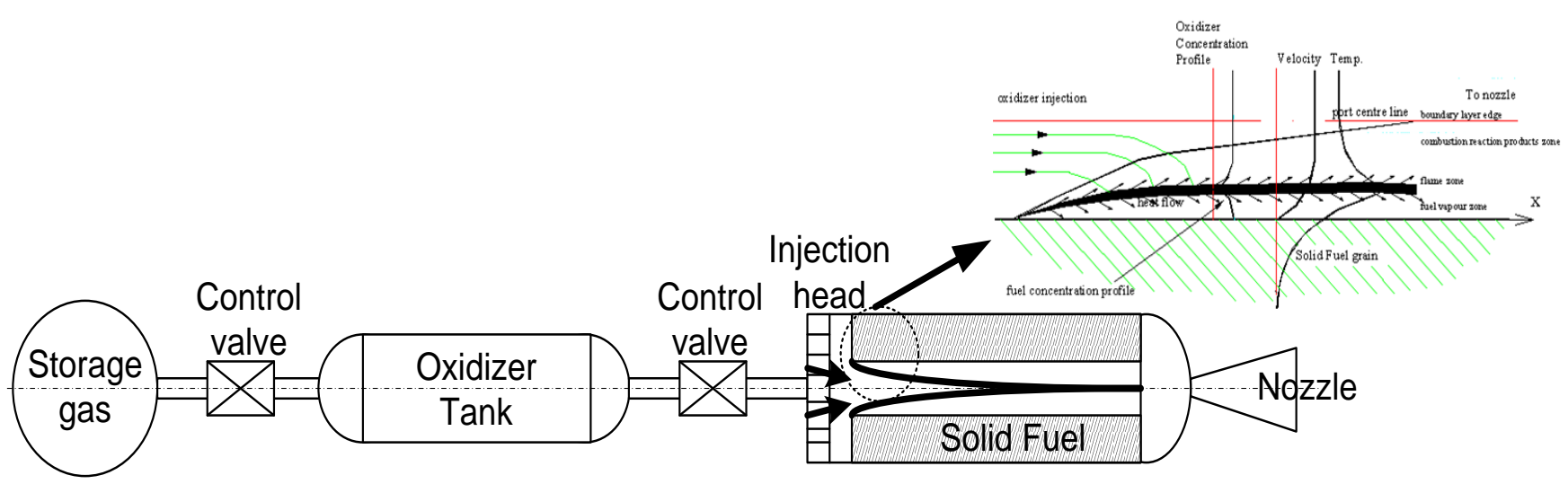

Fig. (1) General scheme hybrid rocket system

Table (1) Regression behavior of solid and hybrid rocket motors

\begin{tabular}{|l|l|l|}
\hline \multicolumn{1}{|c|}{ Solid rocket motor } & \multicolumn{1}{|c|}{ Hybrid rocket motor } \\
\hline $\begin{array}{l}\text { Dominating combustion } \\
\text { mechanism. }\end{array}$ & -Chemical kinetics. & $\begin{array}{l}\text {-Heat transfer (convective and } \\
\text { radiative). }\end{array}$ \\
\hline Main governing parameter & $\begin{array}{l}\text {-Combustion chamber pressure. } \\
\text {-Clamping (ratio of burning area to } \\
\text { port area) }\end{array}$ & $\begin{array}{l}\text {-Oxidizer mass flux, } \mathrm{G}_{\text {ox }} \text { (oxidizer mass } \\
\text { flow rate and geometry of solid fuel } \\
\text { grain). }\end{array}$ \\
\hline $\begin{array}{l}\text { Other parameters } \\
\text { influencing the regression } \\
\text { rate. }\end{array}$ & $\begin{array}{l}\text {-Combustion temperature. } \\
\text {-Particle size of oxidizer. } \\
\text {-Propellant composition. } \\
\text {-Initial grain temperature. } \\
\text {-Gas velocity. }\end{array}$ & $\begin{array}{l}\text {-Composition of solid fuel grain. } \\
\text {-Melting point. }\end{array}$ \\
-Propellant configuration. & -Flame temperature. \\
\hline
\end{tabular}

\section{2: HYBRID PROPELLANT REGRESSION RATE}

Until now, regression rates of conventional solid fuels have typically been an order of magnitude lower than of solid propellants [1]. Throughout HRM combustion, the boundary layer is formed above the SFG surface. This layer is fed by the oxidizer entering from the side of the channel axis and by gasified fuel entering from the grain surface, as shown in Figure (1).

Fuel is partially decomposed and evaporated (gasified) at the solid surface by convective and radiative heat transfer, then it diffuses inward towards the centerline of the combustion volume. Simultaneously, gaseous oxidizer diffuses outward from the centerline through the 
turbulent boundary layer. At a point where the ratio of oxidizer to fuel $(\mathrm{O} / \mathrm{F}$ ratio) concentration is somewhat at fuel-rich side of a stochiometric, combustion occurs in a layer where thickness is of the order of $10 \%$ of the boundary layer thickness.

\section{2-1: Regression Rate Empirical Formulas}

The SF surface regression occurs in a direction normal to the burnt surface. A considerable number of expressions proposed by different authors are found. Some of these expressions are presented here to examine the different factors that govern the regression rate.

Humble and Altman [6] expressed the regression rate $\dot{r}_{f u}$ as:

$$
\dot{r}_{f u}=a G_{\text {tot }}^{n} L_{f u}^{m}
$$

Where, $L_{f u}$ is the fuel grain length and $G_{t o t}$ is the sum of oxidizer and fuel fluxes. The constants $\mathrm{a}, \mathrm{n}$ and $\mathrm{m}$ are characteristic of the propellant.

Waidmann [7] expressed the $\dot{\mathrm{r}}_{\mathrm{fu}}$ as:

$$
\dot{r}_{f u}=a P_{c}^{\alpha} G_{t o t}^{n}\left(C_{t h}^{*}\right)^{q}
$$

Where, $\alpha, \mathrm{n}$ and $\mathrm{q}$ are constants, $\mathrm{P}_{\mathrm{c}}$ chamber pressure and $\mathrm{C}_{\text {th }}^{*}$ theoretical characteristic velocity.

Smoot and Price [8] proposed three different forms, according to the magnitude of the total mass flux:

$$
\left.\begin{array}{ll}
\dot{r}_{f u}=a G_{o x}^{0.8} & \text { for low flux value } \\
\dot{r}_{f u}=\frac{a b G_{o x}^{0.8} P_{c}^{n}}{a G_{o x}^{0.8}+b p_{c}^{n}} & \text { for medium flux value } \\
\dot{r}_{f u}=a p_{c}^{n} & \text { for high flux value }
\end{array}\right\}
$$

In the region of small $\mathrm{G}_{\mathrm{ox}}<\left(10^{-1} \mathrm{~kg} \mathrm{~m}^{-2} \mathrm{~s}^{-1}\right)$, the $\dot{\mathrm{r}}_{\mathrm{fu}}$ is influenced by the heat transfer in the turbulent boundary layer. It does not depend on the combustion pressure.

In the transient region of smaller $\mathrm{P}_{\mathrm{c}}$ and modest $\mathrm{G}_{\mathrm{ox}} \in\left(10 \sim 800 \mathrm{~kg} \mathrm{~m}^{-2} \mathrm{~s}^{-1}\right)$, the $\dot{\mathrm{r}}_{\mathrm{fu}}$ depends on both the oxidizer mass flux and the combustion pressure $\mathrm{P}_{\mathrm{c}}$.

In the region of higher $\mathrm{G}_{\mathrm{ox}}>\left(800 \mathrm{~kg} \mathrm{~m}^{-2} \mathrm{~s}^{-1}\right)$, the $\dot{\mathrm{r}}_{\mathrm{fu}}$ is influenced by $\mathrm{P}_{\mathrm{c}}$ and does not depend on $\mathrm{G}_{\mathrm{ox}}$.

The simplified formula for the $\dot{r}_{f u}$ is:

$$
\dot{r}_{\mathrm{fu}}=\mathrm{a} \mathrm{P}_{\mathrm{c}}^{\alpha} \mathrm{G}_{\mathrm{tot}}^{\mathrm{n}}
$$

If the $\mathrm{G}_{\mathrm{ox}}$ is considered, the formula of regression rate becomes.

$$
\dot{r}_{\mathrm{fu}}=\mathrm{a} \mathrm{P}_{\mathrm{c}}^{\alpha} \mathrm{G}_{\mathrm{ox}}^{\mathrm{n}}
$$

The constants a, $\mathrm{n}$ and $\alpha$ depend on the propellant.

The parameters $\mathrm{a}, \mathrm{n}$ and $\alpha$ are determined experimentally by measuring the regression rates at different values of $\dot{m}_{o x}$ and $\mathrm{P}_{\mathrm{c}}$. The practical values in this expression are $\dot{\mathrm{r}}_{\mathrm{fu}} \in(1.3-5.1)$ $\mathrm{mm} / \mathrm{s}, \mathrm{n} \in(0.4-0.7)$ and $\alpha \in(0-0.25)$ [9].

The mass flux exponent $\mathrm{n}$ is of a main interest, because it has significant effects on the operating conditions. In some cases, the pressure effect is negligible $(\alpha \approx 0)$ and therefore, equation (5) is simplified to:

$$
\dot{r}_{f u}=a G_{o x}^{n}
$$


In conclusion, the essential parameters that affects the $\dot{\mathrm{r}}_{\mathrm{fu}}$ are the oxidizer mass flux $\mathrm{G}_{\mathrm{ox}}$, fuel grain port diameter $\mathrm{D}_{\mathrm{po}}$ and the combustion chamber pressure $\mathrm{P}_{\mathrm{c}}$. It is also slightly affected by initial temperature of the fuel grain $\mathrm{T}_{\mathrm{su}}$.

\section{2-2: Modification of Regression Rate}

To achieve advanced regression rates, it is important to understand which determining factors are involved. Elementary considerations show that $\dot{r}_{f u}$ is determined by the quantity of heat transferred to the fuel surface relative to the heat needed for complete gasification of the fuel surface. Low values of the latent heats of melting and vaporization tend to increase the $\dot{r}_{f u}$. Also high temperature in the combustion zone (flame zone) enhance the $\dot{r}_{f u}$ at a short distance from the fuel surface.

The trials to increase regression rates started in the 1960s when both ammonium perchlorate $\left[\mathrm{NH}_{4} \mathrm{CIO}_{4}(\mathrm{AP})\right]$ and ammonium nitrate $\left[\mathrm{NH}_{4} \mathrm{NO}_{3}(\mathrm{AN})\right]$ were employed as fuel additives [10]. Various other energetic additives such as metal particles (Lithium (Li), Beryllium (Be), Boron (B), Magnesium (Mg), Aluminum (AL)), black carbon, organic compounds, RDX and HMX have been added to conventional fuels to increase generating an exothermic reaction in the vicinity of the propellant surface. Although this approach is effective, its main deterrent is that manufacturing, handling, and shipping costs can be increased due to an increased hazard classification.

The criteria for selection of additives are essentially as heat of combustion, physical properties, high thermal conductivity, low specific heat, low latent heat of fusion, low density, and melting point.

The main advantages of $\mathrm{Al}$ are the relatively high thermal properties (heat of oxidation $=31.1$ $\mathrm{kJ} / \mathrm{gm})$, relatively high density $\left(2.7 \mathrm{~g} / \mathrm{cm}^{3}\right)$ [11], ease of processing, availability, relatively low cost and ease of ignition in the hot combustion environment of the rocket motor chamber. These properties make $\mathrm{Al}$ an attractive additive in our present work for increasing the performance of a propulsion system, especially for a volume-limited system.

The designer selects a propellant type that is likely to give the required performance, cost, mechanical properties as well as the necessary storage stability and the best safety properties (non-toxic and smokeless).

\section{3: THEORITICAL STUDY PROGRAM}

In this section, the metalized solid fuel $\dot{r}_{f u}$ for HRM mathematical model and computer program in addition of thermo-chemical calculations are introduced.

\section{3-1: Thermo-chemical Code}

Table (2) shows the main characteristics of PE and Al materials. The theoretical performance of the hybrid propellant combustion was studied and discussed for PE with $\mathrm{Al} \%+\mathrm{GO} 2$ using a standard thermo-chemical code $\left(\mathrm{I}_{\mathrm{sp}}\right.$ code) [11].The stoichometric ratio for PE with GO2 is 3.4 and sample of performance characterizes (characteristic velocity $\mathrm{C}^{*}$, chamber temperature $\mathrm{T}_{\mathrm{c}}$ ) are plotted for different mixture ratios $(\mathrm{O} / \mathrm{F})$ as shown in Figure (2-a,b).

The pressure ratio (chamber $\mathrm{P}_{\mathrm{c}}$ and atmospheric $\mathrm{P}_{\mathrm{a}}$ ) is an important parameter. According to the thermo-chemical calculations, the specific heat ratio $\gamma$ is $\approx 1.20-1.32$ for all of the $\mathrm{PE}+$ $\mathrm{Al} \%+\mathrm{GO}_{2}$ propellants. The critical pressure ratio to maintain sonic flow at the throat is given by:

$$
\frac{P_{c}}{p_{a}}=\left(\frac{\gamma+1}{2}\right)^{\frac{\gamma}{\gamma-1}}
$$

The value of this ratio is over 1.77 , giving $\mathrm{P}_{\mathrm{c}}$ about 2 bar for standard conditions. 
Table (2) The Main Characteristics of PE, Al and PMMA Materials

\begin{tabular}{|l|c|c|}
\hline Parameters & PE & Al \\
\hline Molecular formula & $\left(\mathrm{C}_{2} \mathrm{H}_{4}\right)_{\mathrm{n}}$ & $\mathrm{Al}$ \\
\hline Molecular weight $(\mathrm{Kg} / \mathrm{K} \mathrm{mol})$ & 28.05 & 26.98 \\
\hline Density $\left(\mathrm{Kg} / \mathrm{m}^{3}\right)$ & 940 & 2700 \\
\hline Melting point $(\mathrm{k})$ & 450 & 660 \\
\hline Heat of combustion $(\mathrm{MJ} / \mathrm{Kg})$ & 46.4 & 10.71 \\
\hline Standard heat of formation $(\mathrm{KJ} / \mathrm{mol})$ & -58.6 & 0 \\
\hline
\end{tabular}

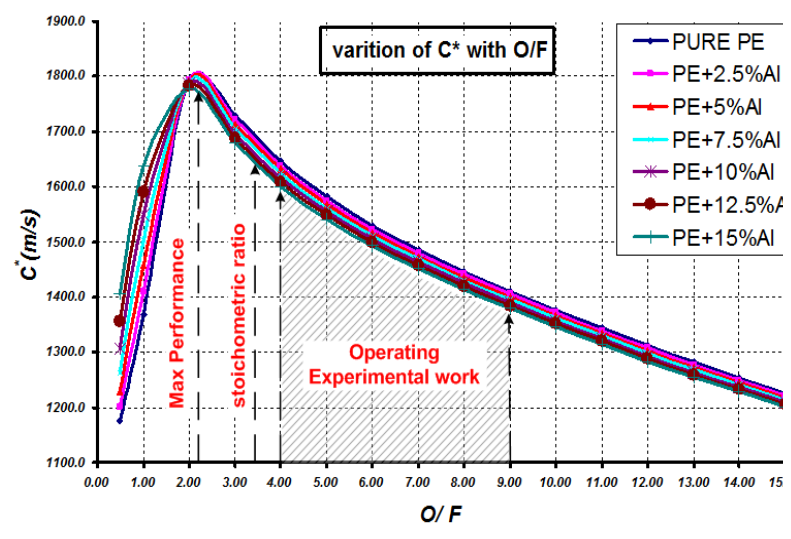

(a) variation of $\mathrm{C}^{*}$ With $\mathrm{O} / \mathrm{F}$

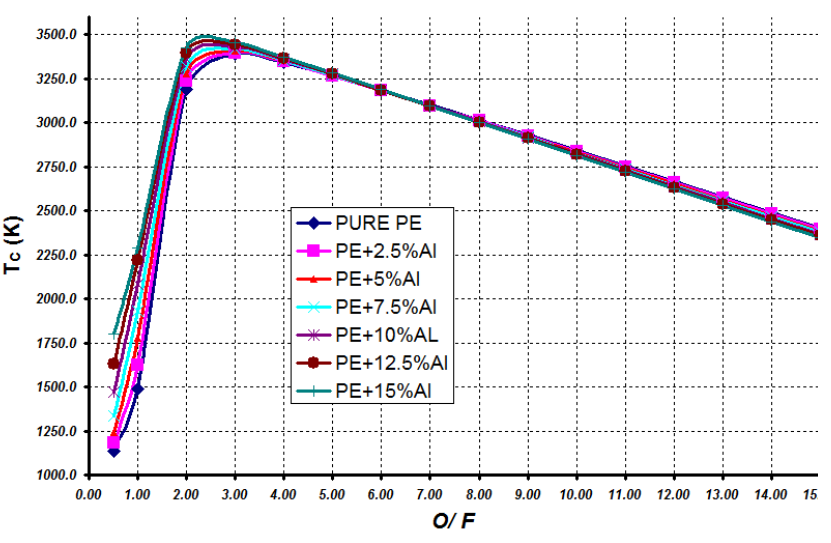

(b) variation of $\mathrm{T}_{\mathrm{C}}$ With $\mathrm{O} / \mathrm{F}$

Fig. (2) $\mathrm{PE}$ with $\mathrm{Al} \%+\mathrm{GO} 2$ thermo-chemical calculation

\section{3-2: Metalized Fuel Grain Regression Rate mathematical Model}

The rate of $\dot{r}_{f u}$ is governed by the rate at which heat is transferred from the flame zone to the fuel surface rather than by grain configuration with chemical kinetics of the reaction.

In HRM, regression rate combustion gases containing large numbers of partial combustion solid particles, an important part of the energy absorbed by the fuel surface may be radiant heat. The $\dot{r}_{f u}$ described in equation (8), represents the coupling that occurs between convection $\dot{Q}_{C}$ and radiation $\dot{Q}_{r}$ heat transfer from a thin diffusion flame zone to the solid fuel grain surface, given by equations (9) and (10) as follows [8, 12]:

$$
\begin{gathered}
\rho_{v} \dot{r}_{f u}=\rho_{f u}(1-k) \dot{r}_{f u}=\left(\frac{\dot{Q}_{c}}{h_{v e f f}}\right)\left[\left(\frac{\dot{Q}_{r}}{\dot{Q}_{c}}\right)+e^{-\frac{\dot{Q}_{r}}{\dot{Q}_{c}}}\right] \\
\dot{Q}_{c}=0.036\left(\frac{\dot{m}_{g}}{A_{p o}}\right)^{0.8}\left(\frac{x}{\mu}\right)^{-0.2} h_{v e f f} \beta^{0.23} \\
\dot{Q}_{r}=\alpha \varepsilon T_{r}^{4}\left(1-e^{-\alpha N}\right)
\end{gathered}
$$

Where $\rho_{v}$ bulk density of volatile component of fuel grain, K...mass fraction of non-volatile surface material, $\dot{\mathrm{m}}_{\mathrm{g}}$ total gas flow rate, $\mathrm{A}_{\mathrm{po}}$ effective port area, $\alpha$ empirical radiation coefficient, $\varepsilon$ emissivity of the fuel grain surface, $\mathrm{T}_{\mathrm{r}}$ effective radiation temperature and $\mathrm{N}$ radiation parameter.

The total gas flow $\dot{\mathrm{m}}_{\mathrm{g}}$ can be described by 3 cases of combustion sates with function of combustion products stream along combustion channel $\dot{\mathrm{m}}_{\mathrm{g}}=\mathrm{f}(\mathrm{x})$ as [12].

Case (1): volatile with particulate combustion products 


$$
\dot{\mathrm{m}}_{\mathrm{g}}=\dot{\mathrm{m}}_{\mathrm{o}}+\left(1-\frac{\mathrm{k} \zeta}{1-\mathrm{k}}\right) \int_{0}^{\mathrm{x}} \rho_{\mathrm{v}} \dot{\mathrm{r}} \mathrm{P} \mathrm{dx}
$$

Case (2): If particles in the grain produce particulate combustion products.

$$
\dot{\mathrm{m}}_{\mathrm{g}}=\dot{\mathrm{m}}_{\mathrm{o}}+\frac{1}{1-\mathrm{k}} \int_{\mathrm{o}}^{\mathrm{x}} \rho_{\mathrm{v}} \dot{\mathrm{r} P} \mathrm{dx}
$$

Case (3): If particles in the grain produce only gaseous combustion products

$$
\dot{\mathrm{m}}_{\mathrm{g}}=\dot{\mathrm{m}}_{\mathrm{ox}}+\left(1-\mathrm{k}_{1}-\mathrm{k}_{1} \zeta_{1}\right) \int_{0}^{\mathrm{x}} \rho_{\mathrm{v}} \dot{\mathrm{r}}_{\mathrm{fu}} \mathrm{Pdx}
$$

Where, $\mathrm{K}_{1}$ mass fraction constant, $\mathrm{P}$ internal perimeter of fuel grain, the factor $\zeta$ and $\zeta_{1}$ accounts for the mass of oxidizer consumed in producing these particles.

The local mixture ratio at the flame zone is estimated by $3 / 4$ stochiometric $\mathrm{O} / \mathrm{F}$ [12]. It is considered dependent of axial fuel grain length. The effective wall emissivity $\varepsilon=0.90$ as estimated by Muzzy [13]. Figure (3) describes block diagram of computer program.

\section{3-3:Case Study}

The $\dot{r}_{f u}$ software program has been applied to the case of a SSHRM with the following data: $\dot{\mathrm{m}}_{\mathrm{ox}}=9.3 \mathrm{gm} / \mathrm{s}, \mathrm{L}_{\mathrm{fu}}=80 \mathrm{~mm}, 2.5 \% \mathrm{Al}$ additives, $\mathrm{d}_{\mathrm{po}}=5 \mathrm{~mm}$ and firing time $=5 \mathrm{~s}$.

The typical program input includes: theoretical $\mathrm{C}^{*}$ data for $(\mathrm{PE}+2.5 \% \mathrm{Al})$ solid fuel material with GO2 combustion, fuel and oxidizer characteristics, the basic motor dimensions, the basic performance constants and other input variables necessary for the computations. The typical main output indicates the transient values along the fuel grain and operating time.

Table (3) summarizes the average calculated performance parameters and the time variations of performance parameters, they are given in Figures (4) through (7).

Table (3) Summary of the Average Calculated Performance Parameters

\begin{tabular}{|l|c|}
\hline Average Performance Parameter & Value \\
\hline Operating Pressure (bar) & 4.81 \\
\hline Regression Rate (mm/sec) & 0.5994 \\
\hline Mixture Ratio (-) & 6.9 \\
\hline Fuel Port Radius (mm) & 5.32 \\
\hline
\end{tabular}




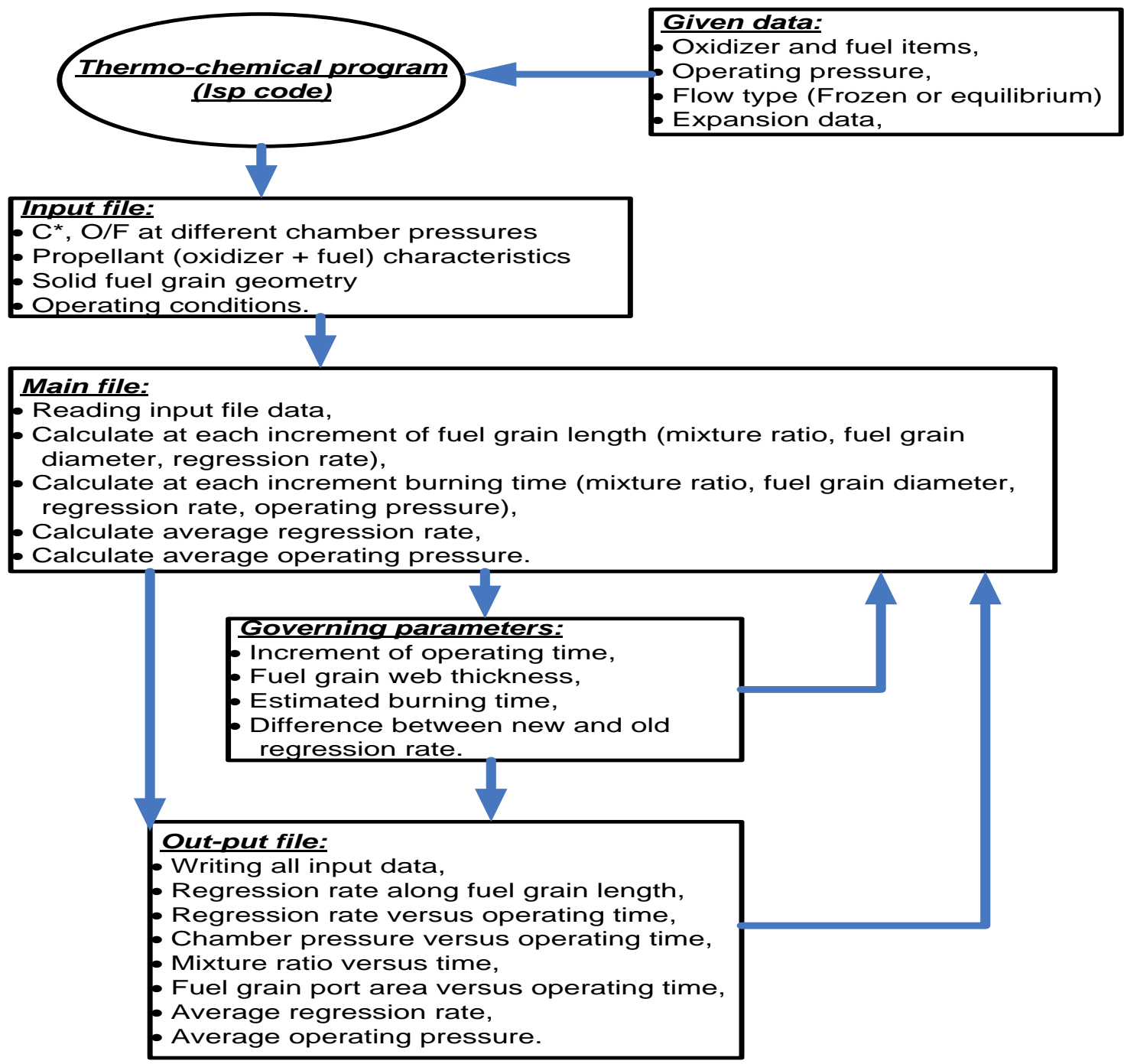

Fig. (3) Block Diagram of Computer Program

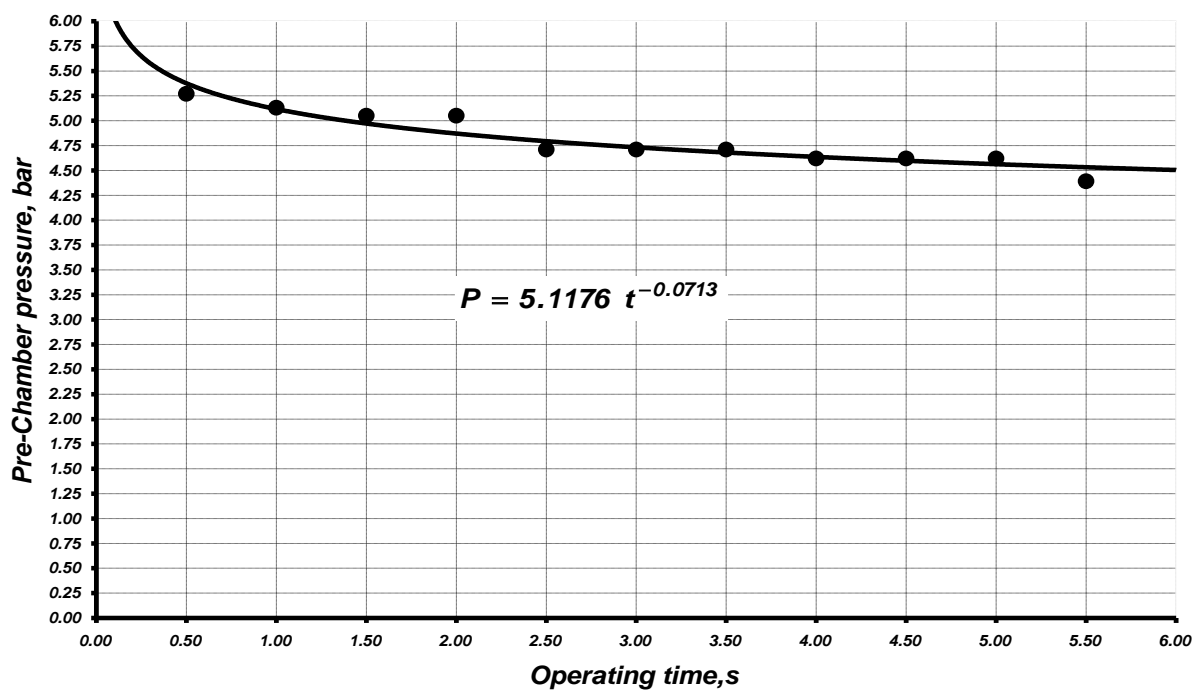

Fig. (4) Calculated $P_{c}$ with Operating Time 


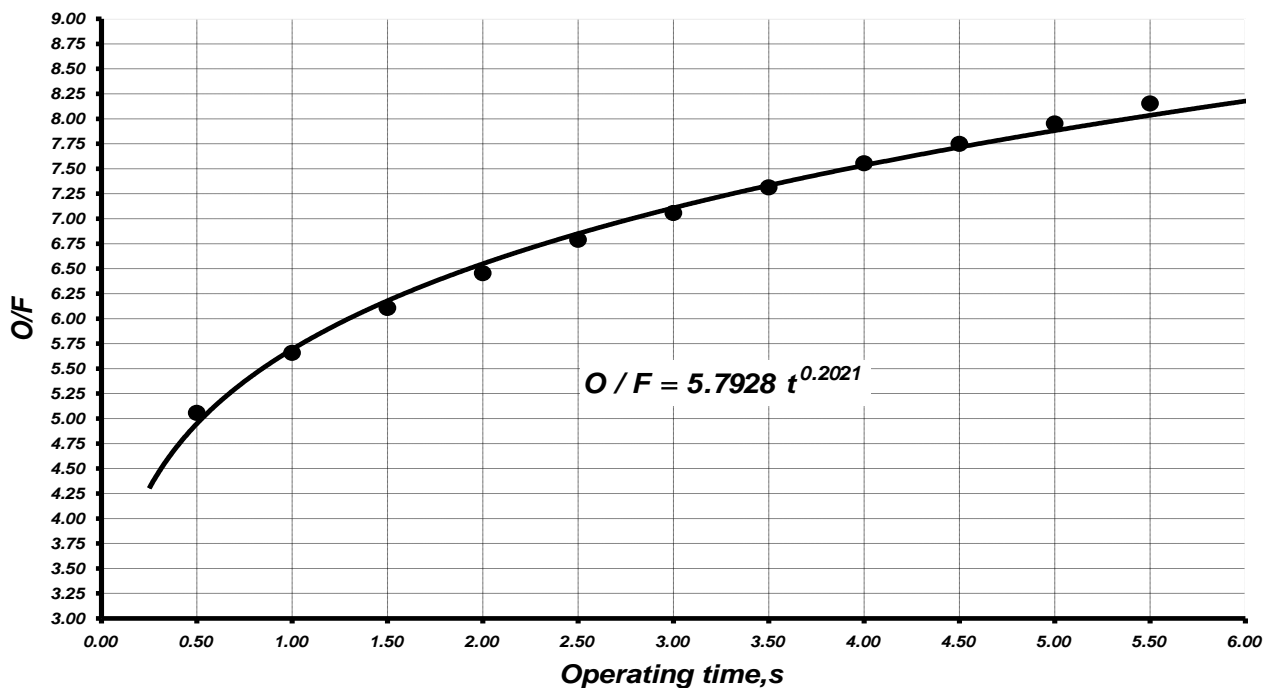

Fig. (5) Calculated Average O/F with Operating Time

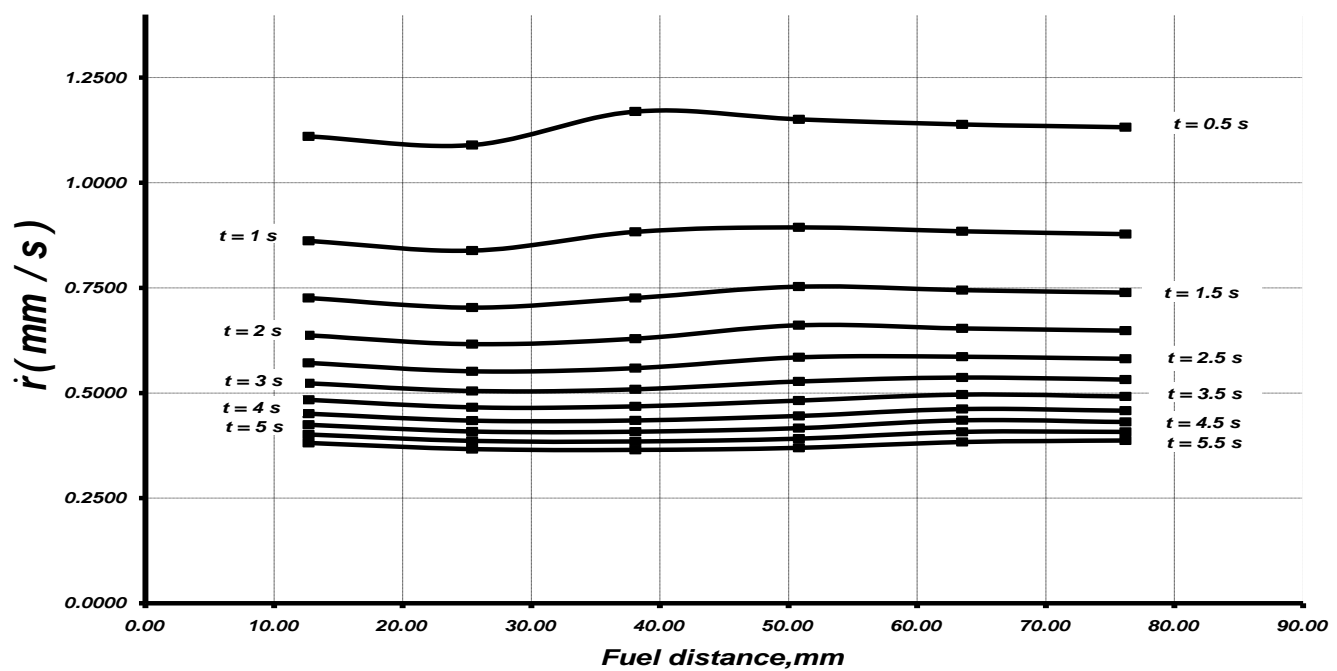

Fig. (6) Variation of $\dot{r}_{f u}$ Along fuel grain

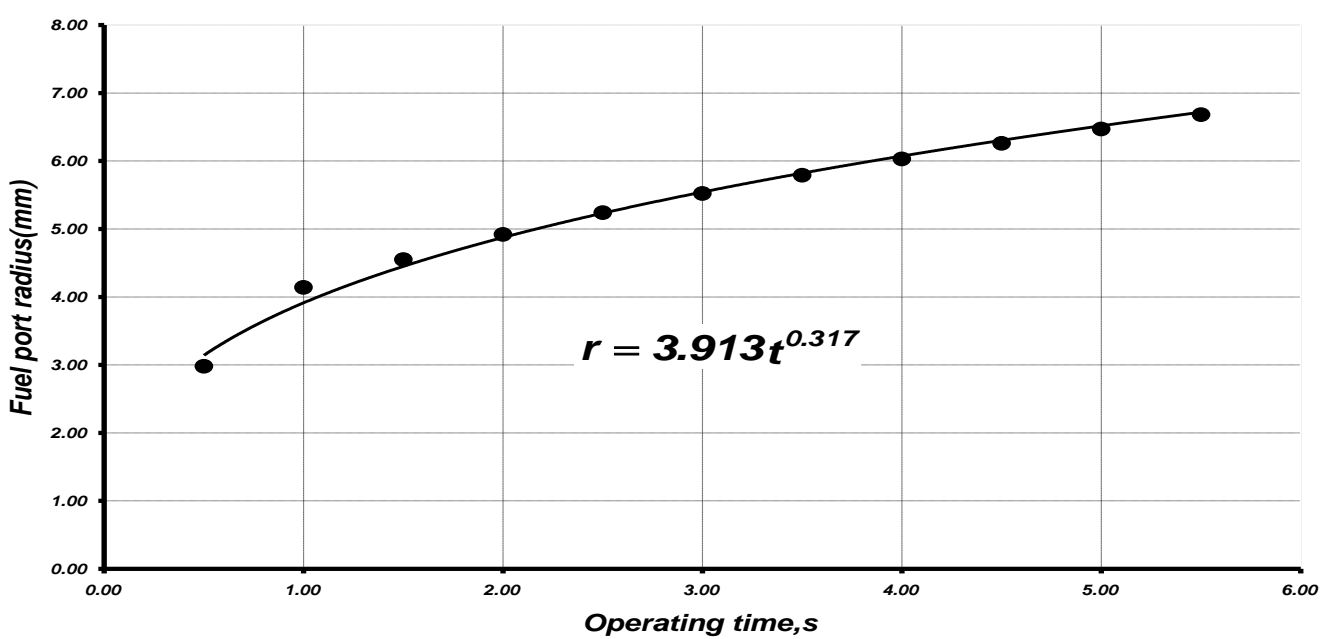

Fig. (7) Variation of Fuel Port Radius Along grain

\section{4: EXPERIMENTAL WORK}

The direct goal of the experimental work is to check the validity of the $\dot{r}_{f u}$ mathematical model in case of metal powder additives and evaluating the performance of a designed SSHRM. 
Factors of performance, safety, operability and cost need to be considered for any given application. Generally, the development, production and operation costs of the system play a major role in the selection of the propellant combination. It is initially chosen as a PE solid fuel for experimental and research due to availability, good casting and machinability, low cost, acceptable performance, the combustion products are environmentally safe $\left(\mathrm{H}_{2} \mathrm{O}\right.$ and $\mathrm{CO}_{2}$ ), long storage without any change of physical and chemical properties.

However, a main advantage of using AL powder with PE material in hybrid motor practical work is the low smoke and toxicity content in exhaust gases, and low price.

\section{4-1: Small Scale HRM}

A SSHRM has been designed, manufactured and tested, with different initial port diameter of fuel grain $(5.0,20.0$ and $28.0 \mathrm{~mm}$ ) and different $\mathrm{Al}$ powder percentages $(2.5,5.0,7.5,10.0$, 12.5, and $15.0 \%$ ). The used propellant was PE in the form of a tubular grain as fuel and GO2 as oxidizer.

The experiments took place for chamber pressure up to 15 bar, firing duration about $5 \mathrm{sec}$, fuel grain length about $75 \mathrm{~mm}$, oxidizer mass flow rate up to $14 \mathrm{~g} / \mathrm{s}$.

Figure (8) describes SSHRM oxidizer gas supply system. Normal industrial GO2 bottles with maximum pressure 100 bar are used.

The control solenoid valve in the supply line opened and closed from the control room by $220 \mathrm{~V}$. Moreover, the solenoid valve and ignition spark are engaged from relay switch connected to make sure that combustion chamber is fully loaded of GO2 before ignition spark. A copper pipeline of $6 \mathrm{~mm}$ outer diameter is used for the high-pressure line, and a tube from hard rubber material is used at the low-pressure line. For best sealing, Swagelok fittings are used. The SSHRM system is operated from control room at atmospheric conditions $20 \pm 5$ ${ }^{\circ} \mathrm{C}$.

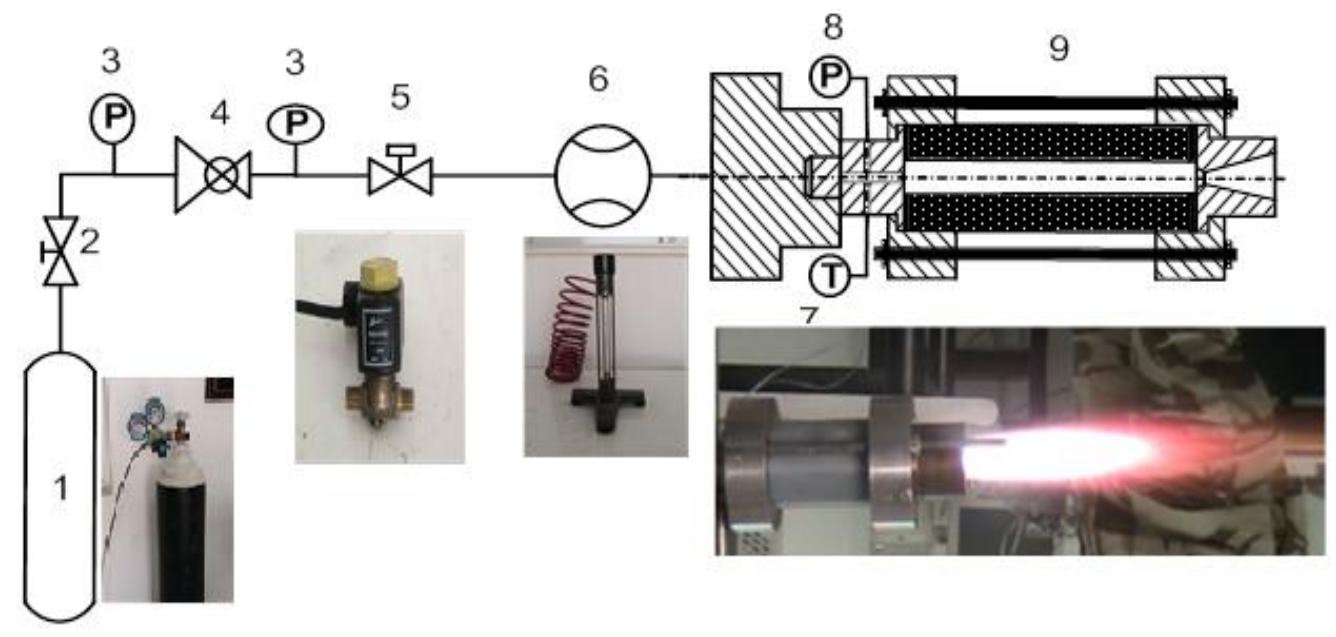

1-Oxidizer Tank, 2- Needle Valve, 3- Pressure Gage, 4- Pressure Regulator,

5- On-Off Valve,6- Rota-Meter, 7- K-Type Thermocouple, 8- Pressure

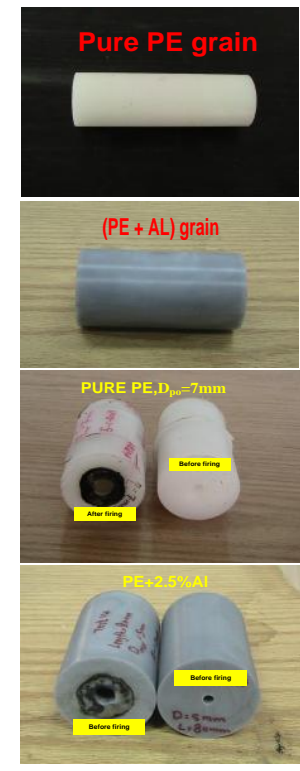

Transducer,

9- Hybrid Rocket Motor

\section{4-2: Static Firing Tests}

Fig. (8) SSHRM Feeding System

The SSHRM should pass a series of cold tests and the hot testing of the SSHRM is accomplished, through large number of experiments to investigate $\dot{r}_{f u}$ of PE with different Al powder percentages. The laboratory test facility comprises two parts:

1) Test stand zone (test bed, camera, feeding system and safety area) Figure (9). 
2) Control room (computer system, recording data accession (DMC plus program), and calibration instrumentations for pressure transducer and temperature thermocouple).

The system allows the measuring of pressures (GO2 tank, feed line, pre-chamber), flow rates of $\mathrm{GO}$; ; and temperature in the pre-chamber during the test run. In addition, other variables are measured before and after a test run, these variables are ambient temperature, nozzle throat diameter and mass of the fuel grain using digital balance.

Recorded data of pre-chamber pressure and temperature are shown in Figure (10).

\section{3: Experimental Results}

The measuring and evaluation program (amplifier system DMC plus) has been adapted for the use with the SSHRM, the modifications are based on the following formulations.

The average operating pressure is calculated as:

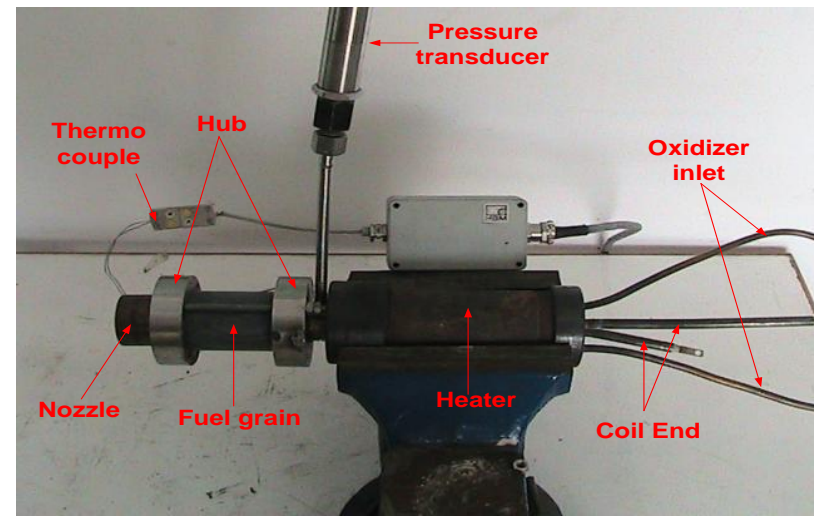

Fig. (9) Laboratory Test Facility

$$
\bar{P}_{a v}=\frac{\int_{t_{1}}^{t_{2}} P_{c}(t) d t}{t_{b u}}
$$

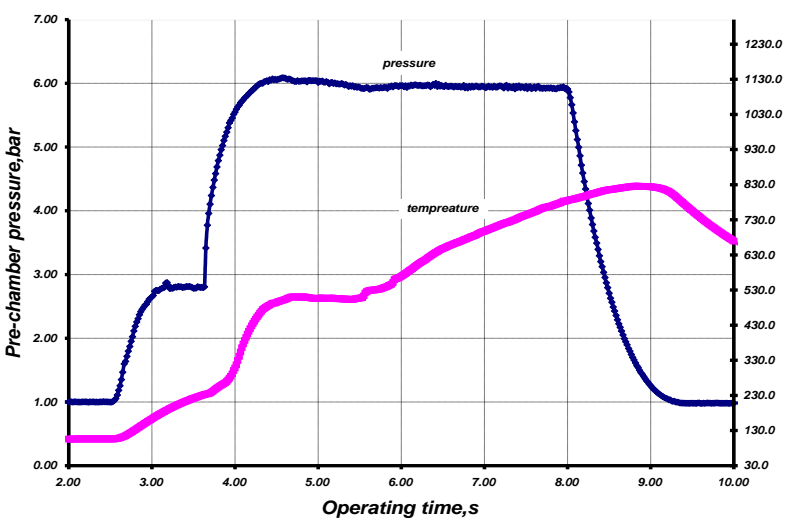

Fig. (10) Experimental pre-chamber pressure and Temperature with Operating Time

The average fuel mass flow is determined according to

$$
\overline{\mathrm{m}}_{\mathrm{fu}}=\frac{\Delta \mathrm{m}_{\mathrm{fu}}}{\mathrm{t}_{\mathrm{bu}}}
$$

Where, $\Delta \mathrm{m}_{\mathrm{fu}}$ is the fuel consumption obtained by weighing SFG before and after the test. The average $\mathrm{O} / \mathrm{F}$ can be determined:

$$
\mathrm{O} / \mathrm{F}=\frac{\overline{\dot{\mathrm{m}}}_{\mathrm{ox}}}{\overline{\mathrm{m}}_{\mathrm{fu}}}
$$

The Average oxidizer, fuel and total mass fluxes during a test run are obtained as:

$$
\begin{aligned}
& \bar{G}_{o x}=\frac{\left\lfloor G_{o x, i}+G_{o x, f}\right\rfloor}{2} \\
& \bar{G}_{\text {tot }}=\frac{\left\lfloor\bar{G}_{\text {tot,ox }}+\bar{G}_{\text {tot }, f u}\right\rfloor}{2}
\end{aligned}
$$$$
\bar{G}_{f u}=\frac{\left\lfloor G_{f u, i}+G_{f u, f}\right\rfloor}{2}
$$

The average $\dot{r}_{f u}$ is obtained by two different methods, the $1^{\text {st }}$ method is based upon the mass loss of the fuel grain $\Delta \mathrm{m}_{\mathrm{fu}}$ and the $2^{\text {nd }}$ method is based upon the determination of the mean diameter of the channel before and after a test run.

These average regression rates $\dot{r}_{f u}$ of the fuel are given by: 


$$
\begin{aligned}
& \dot{r}_{f u}=\frac{\Delta d_{p o}}{2 \Delta t_{b u}}=\frac{\sqrt{\frac{4\left(m_{f u, i}-m_{f u, f}\right)}{\pi \rho_{f u} L_{f u}}+d_{p o, i}^{2}}}{2 t_{b u}}-d_{p o, i} \\
& \dot{r}_{f u}=\frac{d_{p o, f}-d_{p o, i}}{2 t_{b u}}
\end{aligned}
$$

where, $\rho_{f u}$ is the solid fuel density $m_{f u, i}$ and $m_{f u, f}$ are the initial and final grain masses consecutively, $d_{p o, f}$ and $d_{p o, i}$ denote the final and initial grain port diameter, $t_{b u}$ is the burning time.

Over 50 test runs have been performed; the samples result from static firing tests on SSHRM are given in Table (4) and Figure (11).

\section{Measured data}

Regulator pressure $=10$ bar

Throat diameter $=6 \mathrm{~mm}$

Measured oxidizer mass flow rate $=9.3 \mathrm{gm} / \mathrm{s}$

Fuel grain length $=80 \mathrm{~mm}$

Final port diameter $=10.9 \mathrm{~mm}$

\section{Calculated data}

Ignition time $=0.93 \mathrm{~s}$

Average pressure $=5.29 \mathrm{bar}$

Regression rate $(\Delta$ mass $)=0.7143 \mathrm{~mm} / \mathrm{s}$

Characteristic velocity $($ Exp. $)=1397.3 \mathrm{~m} / \mathrm{s}$

Combustion efficiency $=93.7 \%$

Table (4) Static Firing Results of Hybrid Motor

\section{5: MATHEMATICAL MODEL VALIDATION}

In order to check the validity of the developed mathematical model, the measured experimental data are compared with results obtained from theoretical computation. The comparison shows good agreement, as seen in Table (5), which proves the validity of the developed program, since the maximum error noticed was generally less than $10 \%$.

In Figure (11), the $\mathrm{P}_{\mathrm{c}}$ with time obtained from computer program is compared with the test results. It can be seen that during the first $2 \mathrm{~s}$, the theoretical calculated values are somewhat greater than the values from test. It is observed that the maximum error of about $19.6 \%$ of chamber pressure occurs at the beginning of the burning time, and the error drops to $4.2 \%$ at the end of burning. This can be explained by the fuel grain channel machining tolerance, neglecting fuel regression during the ignition period using heat exchanger (hot air) and the large number of assumed input variables, being too difficult to be accurately estimated.

Table (5) Comparison of Computer and Measured Values

\begin{tabular}{|l|c|c|c|}
\hline Parameter & Program & Measurement & Error \% \\
\hline Chamber pressure $\mathrm{P}_{\mathrm{c}}$, bar & $5.2-4.39$ & 4.31 & 9.5 \\
Regression rate $\dot{\mathrm{r}}_{\mathrm{fu}}, \mathrm{mm} / \mathrm{s}$ & $1.13-0.37$ & 0.71 & 5.6 \\
Mixture ratio $\mathrm{O} / \mathrm{F},(-)$ & $5.05-8.15$ & 6.62 & 0.3 \\
\hline
\end{tabular}

\section{6: ANALYSID AND DISCUSSIONS}

A series of experimental test motor has been fired for different initial port diameters $(5,20$ and $28 \mathrm{~mm}$ ) with constant fuel grain length $(70$ to $80 \mathrm{~mm})$ for burning durations around $5 \mathrm{sec}$. and $\mathrm{Al}$ powder weight percentage additives $(2.5,5.0,7.5,10.0,12.5$, and $15.0 \%)$. 
More smooth fuel grain surface and less soot have been observed when using Al additive. In conclusion, the initial fuel grain port diameter (active channel) and oxidizer mass flow rate is shown to be one of the critical parameters encountered in HRM regression rate.

As seen from Figure (12), the average regression rate decreases with the increase of port diameter. This increase is more significant at lower initial port diameters.

Considering the port diameters from $5 \mathrm{~mm}$ to less than $20 \mathrm{~mm}$, it could be seen that the average regression rate increases with increasing the percentage of $\mathrm{Al}$ powder up to $7.5 \%$. With the percentage of $\mathrm{Al}$ powder higher than $7.5 \%$, the phenomenon is reversed, i.e., the average regression rate decreases with the increase of $\mathrm{Al}$ powder up to $15 \%$. This effect is insignificant at $20 \mathrm{~mm}$ initial diameter up to $28 \mathrm{~mm}$.

Finally, it could be concluded that the addition of $7.5 \% \mathrm{Al}$ powder gives the highest performance for the case under study. Comparing this case $(7.5 \% \mathrm{Al})$ with the base line configuration $(0 \% \mathrm{Al})$ a regression rate increase of $90 \%$ and chamber pressure increase of $40 \%$ were reached.

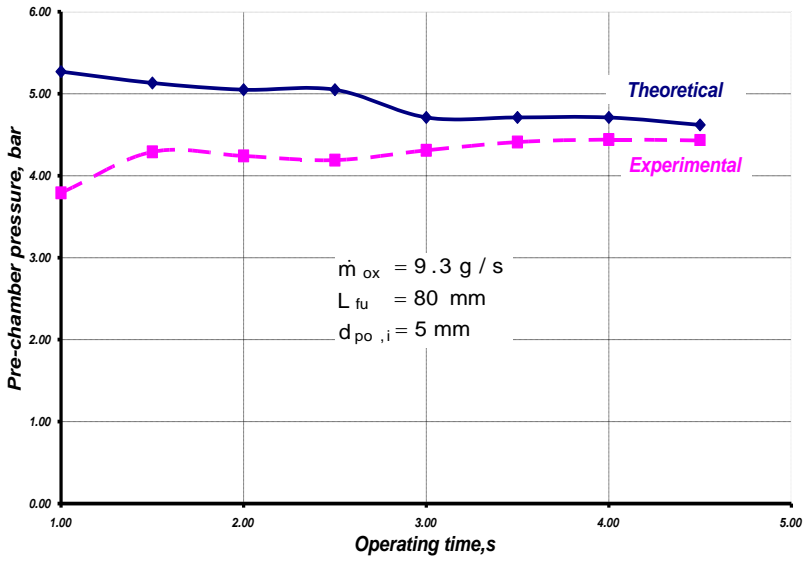

Fig. (11) Experimental and theoretical chamber pressure

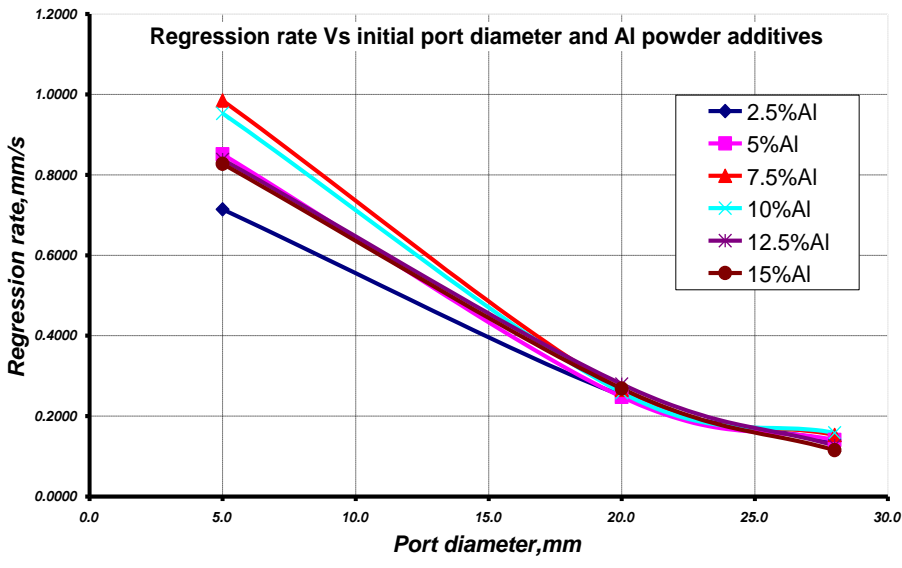

Fig. (12) $\dot{r}_{f u}$ Versus Initial Port Diameter and Al Powder Additives

Making use of the experimental data now available, it is worthy to express the regression rate as function of mass flux with consideration of $\mathrm{Al} \%$ addition. These trends are mathematically expressed to reflect the empirical regression rate as follows:
For $\mathrm{Al} \leq 7.5 \%$
$\dot{\mathrm{r}}=2.0357 \mathrm{G}_{\mathrm{ox}}^{0.5688}(\mathrm{~mm}, \mathrm{gm}, \mathrm{s})$
Eq. (20)
For $\mathrm{Al}>7.5 \%$
$\dot{\mathrm{r}}=1.6657 \mathrm{G}_{\mathrm{ox}}^{0.5417}(\mathrm{~mm}, \mathrm{gm}, \mathrm{s})$
Eq. (21)

\section{7: CONCLUSION}

The objective of the present work is to study the metalized SFG regression rate of the HRM through enhancement of hybrid fuel regression. A SSHRM has been designed, manufactured and used with different initial port diameter of fuel grain and different Al powder percentages. The used propellant was PE or PE+AL in the form of a tubular grain as fuel and gas oxygen as oxidizer.

A mathematical model has been implemented to solve metalized solid fuel regression rate for HRM and metalized combustion phenomena in hybrid system was investigated.

Based on this model, a computer code has been implemented to predict HRM regression rate along fuel grain and versus operating time.

The program was validated through the comparison of predicted and measured pressure histories and performance parameters for a SSHRM, the maximum error noticed was generally less than $10 \%$.

Experimental work lead to the following conclusions: 
- PE is chosen as a solid fuel for performing the experimental work, for its good machinability, low cost, acceptable performance, availability in many forms and environmentally safe combustion products.

- The selection of oxygen as oxidizer is based on quality of handling, storability, transportability, ignition, toxicity, and other parameters.

- The choice of Al powder as energetic material is based on its thermal properties, ease of processing, and relatively low cost.

- The validity of regression rate mathematical model was checked in case of metal powder additives and evaluating the performance of a designed SSHRM.

- Regression rate of hybrid fuel grain was enhanced by addition of Al powder. Adding up to $7.5 \%$ gives the best performance as regression rate increases by $90 \%$ and chamber pressure increases by $40 \%$ compared to basic configuration $(0 \% \mathrm{Al})$.

\section{8: REFERENCES}

[1] David, A., "Hybrid Rocket Development History," AIAA-No. 91-2515, June 24-26, 1991.

[2] Humble, R., Henry, Gary, N.and Larson, Wiley, J., "Propulsion System Analysis and Design," United States Air Force Academy, 1995.

[3] Murthy, K.M., and Jain, S.R., "Studies on Some Novel Hypergolic Hybrid Systems," IAF 87-271, October 10-17, Brighton, UK, 1987.

[4] Website, Space Propulsion Group, "Hybrid Rockets History", URL: http://www.spgcorp.com/News_12.php, 2012.

[5] WWW: forbes.com - www:sciencedaily.com

[6] Humble, R., Henry, Gary, N.and Larson, Wiley, J., "Propulsion System Analysis and Design," United States Air Force Academy, 1995.

[7] Waidmann, W., "Thrust Modulation in Hybrid Rocket Engines," J. Propulsion, Vol. 4, No. 5, Sept.-Oct. 1988

[8] Smoot, L.D. and Price, C.F., "Regression Rate Mechanisms of Non-Metalized Hybrid Fuel Systems," AIAA, 2nd Aerospace Sciences Meeting, New York, January 25-27, 1965.

[9] Gany, A., and Timnat, Y.T., "Parametric Study Of a Hybrid Rocket Motor," Israel Journal of Technology, Vol. 10, No. 1-2, PP. 85-96, 1972

[10] David, W, Netzer, "Hybrid Rocket Internal Ballistics" Naval Postgraduate School, Monterey, January 1972.

[11] Selph, C., "Computer Program For Calculation of Complex Chemical Equilibrium Composition," NASA SP-273, United States Air Foece Academy, version, July 1994.

[12] Wolfhard, H.G., Glassman, L., and Leon G., "Heterogeneous Combustion," Technical Papers Based on AIAA, Academic Press, New York, 1964

Muzzy, R.J, "Schlieren and Shadowgraph Studies of Hybrid Boundary Layer Combustion," AIAA Journal, Vol. 1,No. 9, pp.2159-2160, 1963 